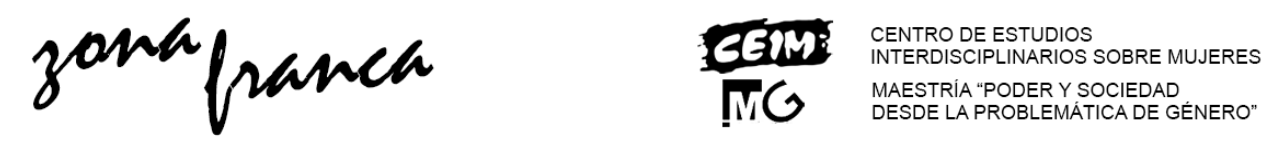

\title{
Extraña pareja. Asedios al binarismo en los relatos periodísticos de Alfonsina Storni y Roberto Arlt
}

\author{
Tania Diz*
}

\section{Resumen}

$A$ inicios del siglo $X X$, el matrimonio se configura en un dispositivo útil en control del sexo, de los placeres y usos del cuerpo; produce identidades fijas y binarias que se suponen a temporales y a históricas. El matrimonio es el vínculo clave de la ideología de la domesticidad ante la que, desde el periodismo, imaginan modos de la resistencia dos escritores tan distintos como Alfonsina Storni y Roberto Arlt. Entonces, propongo un recorrido por sus escritos periodísticos mediante la hipótesis de que ambos perciben y exponen los mandatos que están supuestos alrededor del imaginario del matrimonio, conformando diferentes modos de la resistencia a la ideología de la domesticidad.

Palabras clave: Storni, Arlt, género, literatura argentina, domesticidad.

\section{Strange couple. Assaults on binarism in the journalistic chronicles of Alfonsina Storni and Roberto Arlt}

\section{Abstract}

At the beginning of the 20th century, marriage is the ideal to which all people aspire, with which it turns out to be a useful device in controlling sex, pleasures and uses of the body. It involves fixed and binary identities that are basically timeless and ahistorical. In this article I will analyze the dissimilar modes of resistance that can be read in the chronicles of AlfonsinaStorni and Roberto Arlt, written in the 1920s and 1930s. My hypothesis is that Arlt reproduces to the grotesque the language of

\footnotetext{
*Universidad de Buenos Aires- Consejo Nacional de Investigaciones Científicas y Técnicas. Contacto: taniadiz@gmail.com
}

Diz, Tania. "Extraña pareja. Asedios al binarismo en los relatos periodísticos de Alfonsina Storni y Roberto Arlt" en Zona Franca. Revista del Centro de estudios Interdisciplinario sobre las Mujeres, y de la Maestría poder y sociedad desde la problemática de Género, №28, 2020 pp. 337-364. ISSN, 2545-6504 Recibido: 13 de julio 2020; Aceptado: 14 de octubre 2020

Revista Zona Franca- Centro de estudios interdisciplinario sobre las mujeres (CEIM)- Maestría poder y sociedad desde la problemática de género (MG), Rosario, Argentina. ISSN, 2545-6504 http://zonafranca.unr.edu.ar/index.php/ZonaFrancal Número 28 (2020). 
misogyny while Storni questions the ideas that circulate about the semantic chain that implies marriage-family-engagement. And both of them, with their differences, highlight the artificial character of the links between the sexes, revealing the class and gender mandates that weigh on them.

Keywords: Storni, Arlt, gender, Argentine literature, domesticity.

"Nada tan falso, ante la naturaleza, como el matrimonio. Todo en él es absolutamente convencional"'(2014, 54) decía en 1919 Alfonsina Storni en un claro alegato a favor de la ley de divorcio. El argumento de Storni apunta a develar no solo la realidad efectivamente contractual del mismo, sino que pone en duda cada una de las certezas que este supone. Storni deja ver la compleja trama de sujetos, hábitos, afectos y vínculos que refuerzan la norma heterosexual, tras el matrimonio. Esta norma subyacente se presenta como atemporal, a histórica, única y estable y se transmite por medio de diferentes dispositivos que promocionan, para decirlo en términos de Foucault, el sistema de alianza (1990). Entre los formatos en los que estos ideales se exponen, se hallan los relatos de la domesticidad que se instalan como reproductores de la verdad respecto de lo femenino y de lo masculino. Son discursos que se sostienen desde la apoliticidad y recortan el terreno de acción, en el hogar o en los espacios urbanos de consumo, siendo la política y la esfera pública los ámbitos que corresponden a la identidad masculina. En otras palabras, son relatos fuertemente normativizadores de la heterosexualidad como el único modo identitario y relacional.

La domesticidad es funcional al contrato sexual, que está implícito en el contrato social, (Pateman, 1995), es decir, en la esfera pública; es un producto claro del dispositivo de la sexualidad que produce discursos sobre el sexo, o sea, es una máquina discursiva, scientia sexualis, que se expande a través de diferentes medios

\footnotetext{
' Las crónicas de Alfonsina Storni que se citan pertenecen a dos etapas en las que la escritora escribió columnas femeninas: la primera es en la revista La Nota en 1919 y la segunda es en el diario La Nación en 1921. En esta segunda etapa, la poeta elige el uso de un sugerente seudónimo: Tao Lao. Para ver más sobre él y sobre estas columnas se puede consultar: (Diz 2006; Salomone 2006; Méndez 2017) Todas las citas de las crónicas remiten a la compilación Escritos. Imágenes de género (Storni 2014)
}

Revista Zona Franca- Centro de estudios interdisciplinario sobre las mujeres (CEIM)- Maestría poder y sociedad desde la problemática de género (MG), Rosario, Argentina. ISSN, 2545-6504 http://zonafranca.unr.edu.ar/index.php/ZonaFranca| Número 28 (2020). 
y géneros. Foucault (1990) da cuenta de tres áreas - la pedagogía, la economía y la medicina- que serían las matrices principales de la verdad sobre el sexo, a las que les podemos sumar una importante cantidad de discursos reproductores o divulgadores de estos saberes tales como la puericultura, la economía doméstica, los manuales de educación sexual o las columnas femeninas. Esta ideología se desarrolló en Argentina, en pleno proceso de modernización, con el objetivo de imponer los ideales de la familia de la clase media. Nancy Armstrong (1987) muestra la multiplicidad discursiva - sea ficcional, seudo-científica o periodística - que pone en funcionamiento el dispositivo de la sexualidad a través de la expansión de la industria editorial y produce un ideal femenino: la mujer doméstica. Este modo de escribir delineó un campo de conocimiento y produjo una forma específicamente femenina de subjetividad que se expandió en diversos tipos de relatos. Estos nuevos géneros discursivos, junto con la masificación de la educación, se convirtieron en un instrumento de control social no sólo porque ocupaban las horas de ocio de las mujeres, sino, también porque la experiencia de la lectura era la del aprendizaje del ser femenino. Entonces, la función política de la ficción doméstica fue la de sostener un orden familiar burgués: una unidad social centrada en sí misma y en la que las identidades de género son excluyentes y complementarias a la vez. Así, lo masculino se comprendía en relación a sus cualidades económicas y políticas relativas, y lo femenino, a partir de sus cualidades emocionales relativas. Con el auge de la domesticidad, por consiguiente, surge una nueva forma de ejercer el poder para la mujer porque, dentro del territorio de la casa, es ella la que tiene el control y teje los hilos de las relaciones parentales. Armstrong parte de la premisa foucaultiana de que el sexo no es anterior a su representación, sino que es, más bien, un efecto de éste, y sostiene que la sexualidad es un conglomerado cultural que posee una historia. También, retoma una cuestión que Foucault nombra, pero no desarrolla: la relación entre el avance de las clases medias, la invención del amor y la sexualidad.

Revista Zona Franca- Centro de estudios interdisciplinario sobre las mujeres (CEIM)- Maestría poder y sociedad desde la problemática de género (MG), Rosario, Argentina. ISSN, 2545-6504 http://zonafranca.unr.edu.ar/index.php/ZonaFranca| Número 28 (2020).

Página 339 
A pesar de las obvias distancias entre las novelas inglesas analizadas por Armstrong y el corpus de este trabajo, la domesticidad, también, estuvo directamente vinculada con el establecimiento de las clases medias, incluso, puede decirse que, a través de ella, los ideales de los sectores medios, se universalizan (Nari, 2004). De este modo, la mujer doméstica pasa a ser un arquetipo que atraviesa a las mujeres de todas las clases, edades y razas, un modelo complementario al arquetipo viril que funda el falogocentrismo. (Moreno, 1986) Como afirma Marcela Nari sobre Buenos Aires, en 1920:

Una esposa y una madre, doméstica y domesticada, que intentaba conjurar los temores heredados de la feminidad, disciplinar las prácticas sociales de las mujeres y familiares, y que aportaba una esperanza de "regeneración a la raza", la sociedad y la nación. Esto producía y daba por supuesto una reformulación de las relaciones familiares: el eje clásico de la familia patriarcal (padre-hijo) se desviaba al inalienable binomio natural madre-niño. (Nari, 2004:71)

Tanto en la educación formal, como en la no formal, se consideraba a las labores domésticas, la economía del hogar y el cuidado de los niños como conocimientos que debían poseer las mujeres, ya que se depositaba en ellas, el sostenimiento afectivo y moral del varón y de los hijos. Muchas feministas de la época vieron, en estas enseñanzas, un potencial emancipador para las mujeres de sectores pobres, sobre todo las obreras. Se consideraba que el fin supremo de la domesticidad era la maternidad, al interior del matrimonio, ya que, así, la mujer colaboraba con el progreso de la nación. Según Marcela Nari, no puede afirmarse que la domesticidad haya sido solamente una estrategia de disciplinamiento de las mujeres, por parte de diversos dispositivos de poder vinculados con el Estado, sino que, también, fue un espacio desde donde se dotó de poder a la mujer, probablemente por eso las feministas no se opusieron radicalmente a ésta. De todas

Revista Zona Franca- Centro de estudios interdisciplinario sobre las mujeres (CEIM)- Maestría poder y sociedad desde la problemática de género (MG), Rosario, Argentina. ISSN, 2545-6504 http://zonafranca.unr.edu.ar/index.php/ZonaFrancal Número 28 (2020). 
maneras, en las actas del Primer congreso femenino de $1910^{11}$ figura, como recomendación, que las mujeres no sólo deben aprender las cuestiones relativas a la domesticidad, sino que, también, deben aprender algún oficio, profesión o arte que les permita obtener recursos para sostenerse económicamente. En síntesis, no predomina un rechazo absoluto de lo doméstico, pero sí se manifiesta como urgente el hecho de que la mujer debe ser autónoma intelectual y económicamente.

La promoción y difusión de la domesticidad, como ideales de las clases medias, puede verse a partir de la proliferación de discursos destinados, no sólo a aprender las cuestiones del hogar o a controlar las conductas, sino, también, a partir de una serie de relatos que enseñan a la mujer a serlo. La tautología - enseñar a una mujer a ser mujer- pone en evidencia una contradicción poco inocente: a pesar de que se afirma que la naturaleza de la mujer es afín a lo doméstico, y al mundo de los afectos, ésta debe aprender a realizar las tareas domésticas, a controlar la conducta moral de su marido, a criar a los hijos, y, también, debe adecuar sus actitudes, modos de vestir y pensamientos al arquetipo de la mujer doméstica.

Entonces, cuando Storni se refiere al matrimonio con palabras como "convención" o "falsedad"; permite que surja el cuestionamiento sobre aquello que se impone como verdadero mediante las seductoras analogías que provienen de la naturaleza. En este sentido, Storni se integra a un número impreciso de escritorxs y periodistxs que perciben las imposiciones de este dispositivo y producen desde la resistencia. Para este artículo, propongo recorrer una serie de crónicas de Storni a las que pondré en relación con algunas aguafuertes de Roberto Arlt, mediante la hipótesis de que ambos perciben y exponen los mandatos que están supuestos alrededor del imaginario del matrimonio, conformando diferentes modos de la resistencia a la ideología de la domesticidad.

\footnotetext{
"Ver "Educación doméstica y social de la mujer" por Teresa González Fanning en S/A (2008)) Primer Congreso Femenino. Buenos Aires 1910. Historia, actas y trabajos, Págs. 296-301.
}

Revista Zona Franca- Centro de estudios interdisciplinario sobre las mujeres (CEIM)- Maestría poder y sociedad desde la problemática de género (MG), Rosario, Argentina. ISSN, 2545-6504 http://zonafranca.unr.edu.ar/index.php/ZonaFranca| Número 28 (2020). 
La mujer doméstica es la que encarna estos valores y los lleva adelante en sus diferentes roles de madre, esposa o suegra. Storni describe cruelmente el trabajo de transformación que lleva adelante una mujer- madre sobre su hija, al inscribir la feminidad sobre su cuerpo. Por ejemplo, en una ocasión cuenta Storni que está viajando en subte con una amiga, cuando esta le alerta respecto de una madre y una hija. Storni las mira y descubre azorada el trabajo de producción de la madre sobre la niña: "Las dulces y frescas mejillas cargadas de carmín, perdían su natural frescura para adquirir el aspecto de muñeca barata y ramplona, con que suelen adornarse los escaparates de las tiendas de suburbios." (Storni 2014: 71) Mientras Storni la describe, "la digna mamá, inmóvil al lado de su afeado retoño, paseaba sus ojos sobre los viajeros como reclamando la admiración por su obra, por su dulce obra de madre y de artista..." (Storni 2014: 71)

La madre arregla a la niña para ser mirada por los otros y espera esa aprobación de parte de los pasajeros. Storni la desaprueba haciendo hincapié en la artificiosidad que supone esa tarea, es decir, vuelve nuevamente a la oposición entre lo natural - lo puro e inocente- y lo artificial, que es lo falso, lo atado a las normas. Cuando la niña es una joven, la madre ya no inscribe la cultura sobre su cuerpo, sino que se ocupa de que los gestos, acciones y pensamientos de la niña sean acordes al modelo. Así surge la voz de la madre moralizadora ante una novia dubitativa en "Carta a una novia":

'Hija mía', me dijo: 'las mujeres hemos nacido para casarnos...mi madre lo hizo así, yo, también, lo hice; tú vas a hacerlo ahora. En nuestra casa todas las mujeres han sido virtuosas, obedientes, fuertes...Limpias de alma, serenas, silenciosas, hemos podido vivir entre paredes de cristal... tú eres como las mujeres de tu casa... ha llegado el momento de que sirvas a Dios y a su ley...' ¡Ah, las cosas que me dijo mamá! (Storni 2014: 84)

Revista Zona Franca- Centro de estudios interdisciplinario sobre las mujeres (CEIM)- Maestría poder y sociedad desde la problemática de género (MG), Rosario, Argentina. ISSN, 2545-6504 http://zonafranca.unr.edu.ar/index.php/ZonaFrancal Número 28 (2020). 
La tradición femenina, el respeto por la madre y la abuela es el fundamento que sostiene la aceptación del matrimonio y de los mandatos patriarcales. La voz materna relaciona la feminidad con la obediencia y el matrimonio con sumisión en tanto deberes generacionales. Entonces, Storni rememora estos mandatos maternos, estas inscripciones marcadas en los cuerpos de las hijas, con el fin de mostrar la asimilación de determinadas costumbres que hacen que las mujeres se identifiquen, más tarde, con la mujer doméstica. Arlt desconoce estas instancias de preparación de las jóvenes, pero sí ve con claridad los mandatos que, a través de la joven, le llegan al novio. La madre es ahora la suegra. Storni, desde la relación madre-hija, y Arlt, desde la relación novio-suegra, detectan la pretensión de orientar el comportamiento de los jóvenes. Con palabras de Foucault (1990), sería una relación que encarna al poder controlando al sexo.

En las aguafuertes, las mujeres cobran protagonismo cuando la cuestión es la ideología de la domesticidad: la madre, la esposa, la novia, la hija; es decir, mujeres que tienen un vínculo parental con un varón; construyendo una feminidad patriarcal ya que es el otro del varón. Si bien la novia arltiana pone en acción distintos mecanismos de dominación, es la suegra la que sólo desea someter al novio. Arlt responsabiliza a las mujeres engañadoras y a las suegras obsesivas de esclavizar a los hombres en el matrimonio y deposita la acción malintencionada en la mujer, porque si asocia la sexualidad al dinero (Masotta, 1982) y el dinero a la clase media, la mujer doméstica es la que cobra protagonismo. La maldad de la mujer consiste en colocar al varón en el lugar de ser sexuado, fatalmente relacionado con ella. La escena en que la suegra presiona al pretendiente para que se case con su hija se reitera tanto en su obra periodística como ficcional y, con mayor o menor intensidad, reproduce un discurso marcadamente reconocible en el imaginario social. La dulzura o la persuasión en la suegra de Arlt connota simulación y mentira ante su verdadera intención, que es la de casar a su hija, incluso, ésta pasa a ser un personaje más relevante que el de la novia, con lo cual, elude la

Revista Zona Franca- Centro de estudios interdisciplinario sobre las mujeres (CEIM)- Maestría poder y sociedad desde la problemática de género (MG), Rosario, Argentina. ISSN, 2545-6504 http://zonafranca.unr.edu.ar/index.php/ZonaFranca| Número 28 (2020).

Página 343 
manifestación del deseo sexual y todo se reduce a una relación de fuerzas entre ambos en pos de la novia-hija:

Diálogo entre la presunta suegra y el presunto damnificado. La mercadería, o sea, la hija en estado de merecer, está ausente. La presunta suegra tiene en las arrugas del semblante disuelta la suficiente dosis de miel, vinagre, sal y pimienta, según sea indispensable. La propietaria de la mercadería inyecta o espolvorea en su sonrisa la miel, el vinagre, la sal o la pimienta. El ciudadano, cara de 'bonafide' al 'sugo'. Es otario, pero como todos los otarios, tiene sus cascabeles de vivo. (Arlt 2000, 146)

Masotta (1982), analizando el personaje de la suegra, señala que esas mujeres son seres que encarnan el deseo del ascenso social, de pertenecer a la esfera de los poseedores, a través del casamiento de la hija. Así, las describe como "seres desorbitados", que caricaturizan las contradicciones de la clase media por pretender adscribirse a "la esfera de los poseedores". "Tener no significa solamente tener objetos, sino tener objetos para poseer a través de ellos, a los hombres. Tener es tener hombres." (59) Esto mismo puede decirse de la joven casadera porque el novio, tanto en Storni como en Arlt, es el equivalente de lo que se posee e, incluso, ambos mencionan los mismos índices de status social: la corbata, el auto, un título universitario o el dinero.

En la cita anterior se anuncia el duelo entre la suegra y el novio, es decir, el Bonafide, que, como su nombre lo indica, es un hombre sincero, de buena fe, que cae en las garras de una mujer monstruosa, capaz de dominarlo. Más aún, es más fuerte el duelo con la suegra que el deseo hacia la novia. Así, el novio permanece en una relación de dominación, de humillación que actualiza la frustración y la angustia del hombre de Arlt. Esta interpretación puede complejizarse con el hecho de que la suegra no sólo tiene deseos de ascenso social, sino que, además, cumple la función de controlar la sexualidad masculina por medio de la imposición del matrimonio. Así, está en juego la obediencia o resistencia al dispositivo de

Revista Zona Franca- Centro de estudios interdisciplinario sobre las mujeres (CEIM)- Maestría poder y sociedad desde la problemática de género (MG), Rosario, Argentina. ISSN, 2545-6504 http://zonafranca.unr.edu.ar/index.php/ZonaFrancal Número 28 (2020). 
sexualidad que modela las conductas masculinas, al punto de que hace de los varones; novios y maridos. En este sentido, Arlt está mostrando un mecanismo de coerción de la subjetividad masculina al que pretende resistir por medio del descubrimiento de la comedia.

El Bonafide es el hombre que ingresa en el territorio doméstico: está en el living de la casa, en el espacio intermedio entre el afuera y el adentro, que es dominado por la suegra. El conocimiento que el novio puede tener de la joven es externo y superfluo ya que se limita a la conversación permitida en el living, bajo la mirada atenta de la madre. Ella es la maneja las reglas, que el novio acata o transgrede, es la que mide las conductas masculinas para lograr que funcione la relación seducción y represión al punto de lograr el casamiento. Arlt lee, en términos económicos, la palabra de la suegra al decir que ella quiere vender su hija, al mejor postor. Esto no sólo alude a la asociación entre matrimonio y prostitución, sino que, también, permite ver el resultado de la obra materna: ofrece, de su hija, sus servicios domésticos y sexuales, al habilitar el juego entre lo prohibido y permitido, entre los novios. Además, el Bonafide es llamado, alternativamente, cara de gil, marmota, papanatas enamorado. Como se deduce de estos apelativos, Arlt lo descalifica porque es un gil que ha caído bajo el poder de la feminidad, aún cuando, no responda económicamente a las expectativas de la suegra. Ante el protagonismo de la mujer en el dominio de las relaciones parentales, Arlt recrea un discurso sexista en el que el varón teme perder poder al entrar en ese mundo. La suegra, a la vez, tiene el poder que la ideología de la domesticidad le da, ya que obedece al modelo de la feminidad hegemónica.

En cuanto a la subjetividad masculina, el novio, en las crónicas de Storni, también, es el bien preciado en el futuro, en tanto bien material (corbata, auto), pero, la cronista agrega otro tipo masculino: el que porta una mirada censora sobre comportamiento femenino, o sea, el varón que impone y controla los mandatos de la domesticidad en los cuerpos femeninos, pero que no entra en relación con la mujer, solamente es la "mirada evaluadora" que condena o festeja el ser femenino.

Revista Zona Franca- Centro de estudios interdisciplinario sobre las mujeres (CEIM)- Maestría poder y sociedad desde la problemática de género (MG), Rosario, Argentina. ISSN, 2545-6504 http://zonafranca.unr.edu.ar/index.php/ZonaFranca| Número 28 (2020). 
Así es que lo femenino, tras la madre, cumple con la formación moral y lo masculino, asume la mirada inquisidora que valúa y controla la adecuación al reglamento de género. Este último es el tipo masculino que Storni denomina "hombre fósil":

Hago, pues una reverencia a la vieja lengua y me prometo pasar un tiempo sin volverla a molestar, pues me interesa que hablemos, ahora, de los hombres fósiles, es decir, de aquellos hombres cuyas ideas están casi petrificadas y que parecen vivir todavía en las capas espirituales del medioevo. (...) Tiene además el hombre fósil modalidades que no son más que un residuo de crueldad de la especie, y un absoluto desconocimiento de la causalidad. Se obceca el hombre fósil en que la niña debe ignorarlo todo, fingirlo todo, disimularlo todo, y en claro, así le da razón a Jehová. (Storni 2014: 47)

Así, Storni afirma que la relación entre los sexos es una relación de poder en la que el varón es el que maneja, por fuera, el poder y la mujer es la que se halla sometida a esa relación, en tanto cuerpo sexuado, puro sexo desconocido, que debe ser controlado. Storni muestra la presencia omnipresente de la mirada masculina, pero no inaugura, como Arlt, la guerra, sino que, más bien, apunta a la toma de distancia de este modelo.

Arlt, en otras aguafuertes describe una tipología infinita de subjetividades masculinas de clase media. Es imposible realizar un listado exhaustivo, pero pueden agruparse por ciertos rasgos comunes. En primer lugar, los hombres denominados por su ocupación - el portero, el del quiosco, el policía, el ladrón, el almacenero, el juez, el peluquero, el oficinista, el usurero, el ecónomo, escritor, el quinielero, el desocupado, el vigilante, el médico, el cajero, el teatrero, el estudiante el contrabandista, el doctor, el latero, el de la guitarra, el acompañante, el automovilista, el chico de la oficina, el abogado, el patrón, el ajedrecista, el diputado; en segundo lugar, aquellos que tienen alguna característica física o psíquica - el

Revista Zona Franca- Centro de estudios interdisciplinario sobre las mujeres (CEIM)- Maestría poder y sociedad desde la problemática de género (MG), Rosario, Argentina. ISSN, 2545-6504 http://zonafranca.unr.edu.ar/index.php/ZonaFrancal Número 28 (2020). 
hombre con bigote, con sombrero, el enfermo, el de la camiseta calada, el misántropo, el honrado, el mentiroso, el indeciso-. Y, por último, aquellos que se destacan por un accionar en particular - el que vende la felicidad por un peso, el parlanchín, el que da una mala noticia, el que necesita ladrillos, el que habla de Dios, el que deja pasar el tranvía, el que ocupa la vidriera del café, el manya oreja, el demócrata, el que mira con tristeza, el que silba, el del trombón, el amigo, el que se tira a muerto, el que canta, el que va a los remates, el que no paga-. Entre los numerosos personajes de Arlt, el solterón, o sea, el que tiene decidido no casarse, es el único que celebra la existencia de las mujeres independientes, de esta manera:

Me gustan las muchachitas que se ganan la vida. Son las únicas mujeres que provocan en mí un respeto extraordinario, a pesar de que no siempre son un encanto. Pero me gustan porque afirman un sentimiento de independencia, que es el sentido interior que rige mi vida. (50)

Es significativo que éstas aparezcan en términos positivos en la voz de un personaje que se instala por fuera de las relaciones de alianza. El imperio de la mirada y la relevancia de la apariencia son las dos cuestiones esenciales que hacen posible la relación entre los sexos. Así como Storni señaló el ojo censor masculino que controlaba los movimientos femeninos, Arlt aparece como cronista que mira la circulación de las mujeres en la ciudad. No obstante, también, ve a los hombres. Y en ambos observa su transformación en autómatas domésticos. Incluso, a pesar de que no hace mención explícita a textos puntuales, sí apela a la parodia del instructivo que establece qué vestimentas y gestos deberían adoptar ellos, si desearan entrar en relación con una mujer. Podemos decir que como Storni parodia la performatividad del género en la mujer, Arlt, en "Primeras palabras para conquistar a una dama" detecta esta actuación en el varón:

Revista Zona Franca- Centro de estudios interdisciplinario sobre las mujeres (CEIM)- Maestría poder y sociedad desde la problemática de género (MG), Rosario, Argentina. ISSN, 2545-6504 http://zonafranca.unr.edu.ar/index.php/ZonaFranca| Número 28 (2020). 
Péinese bien a la gomina, déjese unos bigotitos de cepillo de dientes, lleve un traje entallado y una corbata de siete reflejos $y$, si puede, ande en "voiturette" y ríase de Stendhal, de las declaraciones de amor, de las palabras bien coordinadas y de la inteligencia. (125)

En cuanto a la representación de la mujer, en el paso de Storni a Arlt, el referente femenino sufre un cambio nominal: ya no es una niña, sino, que es una mujer. Este cambio obedece a que ambos pertenecen a dos generaciones que han establecido modos de relación con el lenguaje muy diferentes entre sí. En consecuencia, ese uso sería índice de dos estéticas distintas: Arlt usa el lenguaje de la calle, el lunfardo, en cambio, Storni se mantiene en la parodia que señala el agotamiento de "niña", término más antiguo y con remembranzas poéticas del modernismo. Otro aspecto relevante en el cambio de mujer a niña es que señala una cierta relación con la pertenencia a una determinada clase social. Si bien no puede afirmarse que cada uso del término remita a la clase, es usual la asociación del término "niña" con la clase alta o media con pretensiones, y "mujer" para la clase media o baja.

Por último, aunque es probable que no haya una relación directa, no está demás recordar que la mujer en 1930 tenía una participación en la vida pública más legitimada que en la década anterior, por una cuestión jurídica. Quiero decir que, dejando en suspenso las cuestiones estéticas e ideológicas en juego, llamar, hasta 1926, a las mujeres como "niñas" es denominarlas tal y como la ley las considera. Hasta la fecha mencionada, en que se reconocen los derechos civiles de las mujeres, éstas eran seres incapaces de actuar en la vida pública sin el control de un varón, en otras palabras, eran niñas eternas. Ahora bien, a partir de 1926, se las reconoce como seres adultos y pueden administrar sus bienes, tener comercios, firmar cheques, y demás. Más allá de la precisión legal sobre los derechos, Storni considera que las mujeres no son féminas aniñadas, sino que simulan serlo porque no se atreven a asumir una identidad propia y, en este sentido, prefieren adaptarse a la masa.

Revista Zona Franca- Centro de estudios interdisciplinario sobre las mujeres (CEIM)- Maestría poder y sociedad desde la problemática de género (MG), Rosario, Argentina. ISSN, 2545-6504 http://zonafranca.unr.edu.ar/index.php/ZonaFranca| Número 28 (2020). 
La operación arltiana es la afirmación de que la mujer casadera y la suegra son las únicas formas de la subjetividad femenina. Así, Arlt naturaliza el modelo hegemónico, y lo considera universal y atemporal, a pesar de que, en otros momentos, haya reconocido la influencia de variables históricas o, incluso, otros modos de la subjetividad femenina. Entonces, el autor concentra una discursividad en la que la mujer es una seductora irresistible, poco inteligente y ambiciosa, tal como lo explicita en frases como "y después porque no es el hombre el que elige a una mujer ¡no! es la mujer la que elige a su hombre; al que más le gusta. Por capricho y por sexo" o "la mujer no tiene capacidad para juzgar de la inteligencia del hombre" (125) que pertenecen al acervo de los lugares comunes del sexismo.

Ante este referente femenino, Storni elige tres modos de nombrarlo que gradúan la evaluación de la autora sobre el referente. En primer lugar, usa los términos más neutrales posibles, por ejemplo, el que designa el trabajo que realiza - manicuras, profesoras, médicas, costureras, maestras, dactilógrafa, acuarelistaso la relación de parentesco que la identifica - madre, novia, esposa-. En segundo lugar, la nombra dialógicamente mediante los enunciados habituales dentro del estilo de la escritura para mujeres, lo que no es exclusivo de este género, como se ha visto en la crítica literaria contemporánea a la poeta, cuestión que analizamos en el capítulo anterior. En tercer lugar, elige sustantivos que exudan una mirada crítica, indignada, ante el estereotipo femenino.

Con respecto al segundo modo de nombrar, cabe aclarar que estos enunciados son signos constituidos por la unión indisoluble de sustantivos y adjetivos, en los que los referentes -mujeres/ niñas/ muchachas/ jóvenes, casaderas - están marcados por adjetivos - dulces / divinas/ adorables/ preciosasque exaltan la belleza como cualidad esencial de la feminidad desde una mirada masculina. En otras palabras, estos enunciados no son más que variaciones de una frase constante- bello sexo-, que es un cuasi sinónimo de sexo débil. En 1920, estos términos constituían el modo de nombrar a la mujer como género, como se puede leer en las publicaciones periódicas, científicas e, incluso, literarias. En este sentido,

Revista Zona Franca- Centro de estudios interdisciplinario sobre las mujeres (CEIM)- Maestría poder y sociedad desde la problemática de género (MG), Rosario, Argentina. ISSN, 2545-6504 http://zonafranca.unr.edu.ar/index.php/ZonaFranca| Número 28 (2020). 
lo que connotan los adjetivos "bello" y "débil" dentro de la lógica falogocéntrica, (Braidotti 2015) abarcaba a la totalidad de las mujeres. De las crónicas de Storni se desprende que estos enunciados no son términos que definen la subjetividad femenina en general, sino que caracterizan a un tipo particular que se impone como hegemónico. Storni asimila el enunciado "sexo débil" a un tipo femenino superficial y ocioso, cuya única aspiración es el matrimonio y cuyo límite territorial es el hogar. Storni parodia un arquetipo que Elvira López (2009), en su tesis doctoral de 1901, describe como síntoma de la pobreza subjetiva de la mujer porteña:

No falta quienes critiquen, a las porteñas sobre todo, y especialmente a las de las clases pudientes, su educación superficial, su poca inclinación por los estudios serios y las ocupaciones del espíritu; la frivolidad de su carácter y conversaciones que alejan cada vez más de su sociedad a los hombres de espíritu cultivado; su desenfrenado amor por el lujo que causa el asombro de cuantos visitan nuestro país. (227)

Así, el estereotipo de la mujer porteña de clase alta estaba marcado por su superficialidad y tendencia al consumo. En 1910, en el $1^{\circ}$ Congreso Femenino, Dora Mayer menciona al bello sexo como la mujer superficial que seduce con el arreglo de su cuerpo, que hace de sí lo que determina la mirada masculina, pero que carece de pensamientos propios y/o de formación intelectual.

Bastante se ha echado en cara a los miembros del llamado bello sexo la estrechez de su entendimiento y la capacidad limitada de su cerebro. (...) Observo que hasta hoy la mujer ha aprendido el arte de atraer, pero no de cautivar, los afectos del hombre. Conocedora de las exigencias que hace el género masculino, cultiva la belleza y se somete a las costumbres, unas veces con sinceridad y otras con disimulo. La mujer es la obra del hombre, porque vive para él. (Congreso Femenino Internacional de la República Argentina y Asociación «Universitarias Argentinas.» 2008, 264)

Revista Zona Franca- Centro de estudios interdisciplinario sobre las mujeres (CEIM)- Maestría poder y sociedad desde la problemática de género (MG), Rosario, Argentina. ISSN, 2545-6504 http://zonafranca.unr.edu.ar/index.php/ZonaFrancal Número 28 (2020). 
Al decir que la mujer es obra del hombre, Mayer está diciendo que la mujer real se adapta al ideal masculino, deviniendo en el bello sexo en función del deseo masculino. Storni coincide con lo que sostiene Mayer, que puede trasladarse a gran parte del feminismo del Centenario, incluso, deslinda entre la belleza corpórea como una ofrenda femenina que enaltece la virilidad y la belleza espiritual ligada a la inteligencia, por lo tanto, directamente relacionado con la formación de la subjetividad.

Las palabras citadas forman parte de una larga exposición sobre la condición moral de la mujer que diera en el 1 - congreso femenino de 1910. Como muchas de las mujeres- Julieta Lanteri, Elvira López, Elvira Rawson, Sara Justo- que participaron en él, Mayer estaba ligada a los círculos intelectuales. Era de origen alemán, pero vivió en Perú y, a través del periodismo, defendió no sólo los derechos de las mujeres, sino, también, de los indígenas y de los obreros. No casualmente desde Perú, ella relaciona al feminismo con el indigenismo y el socialismo. Elvira López, en la tesis ya mencionada, no registra a la población indígena argentina, pero, sí, a la clase obrera y agrega un tercer movimiento que es síntoma de su mirada más europeísta que americana: el pacifismo. En síntesis, con sus diferencias, estas intelectuales, a inicios de siglo $X X$, reflexionaron sobre la condición femenina, vincularon al feminismo con otros movimientos sociales emergentes, y vieron en éstos signos de progreso, de una evolución casi inexorable en el camino de la modernización. Lamentablemente, este espíritu revolucionario del feminismo argentino va perdiendo fuerza, pero es indudable que Storni lo conocía, tanto por sus vínculos personales, como por su escritura ensayística.

Para Storni, la mujer doméstica es fruto del matrimonio burgués como ideal de la clase media, aún cuando conserve características de la clase alta. Incluso, en "Cuca", uno de los pocos cuentos que escribe, Storni hace explícita la relación entre la mujer doméstica y la clase media al decir: "Cuando pude contenerme guardé silencio para paladear sus palabras: razonaba como una joven común de la clase media y de los veinte años." (Storni, 2014: 359) Su preocupación está más centrada

Revista Zona Franca- Centro de estudios interdisciplinario sobre las mujeres (CEIM)- Maestría poder y sociedad desde la problemática de género (MG), Rosario, Argentina. ISSN, 2545-6504 http://zonafranca.unr.edu.ar/index.php/ZonaFrancal Número 28 (2020). 
en el modo de subjetivación femenina que impone el matrimonio que en la institución misma. Si bien la expresión más común de la mujer doméstica es la joven casadera, Storni demuestra que este estereotipo atraviesa otras tipologías femeninas que forman su universo de discurso: hijas, trabajadoras, lectoras, caminantes, ricas o pobres, extranjeras o nacionales, porteñas o de las provincias. Este fenómeno es el que demuestra Storni con una mirada anclada en el espacio público que supone una tipología extradoméstica, al menos, en apariencia. Si De Beauvoir (1997) dirá en los 50 que no se nace mujer, sino que se llega a serlo, Storni se adelantaba al poner en evidencia el trabajo de producción de las mujeres en el devenir ya no solo "casaderas", sino sobre todo "bellas" ante la mirada masculina. Así, explora la superficialidad hasta definirla como una obsesión femenina por la imitación de la moda que aparece en las columnas femeninas y con otro objetivo: la apariencia de la clase social superior.

Storni, como veremos más adelante, se contagia con la esperanza en la mujer futura que vendría a desalojar a la mujer doméstica en decadencia, en tanto modelo propio de un país atrasado. Por ejemplo, en "La mujer bella", Tao Lao seudónimo de la cronista- distingue entre la belleza del espíritu, que es la que la transforma en un sujeto, y la belleza del cuerpo, que la hace el complemento o el adorno del varón:

El hombre exige, ha exigido siempre, una belleza que represente más o menos alma, conforme a que hubiera en él mayor o menor evolución espiritual. Así entendido, o así presentido, la preocupación constante de la mujer ha sido la belleza. Ella es en parte su dote; en la competencia de ser a ser, lucha al fin de la especie por alcanzar su complemento, la mujer necesita de la belleza - su arma primitiva. (225)

En esta crónica, como en otras, Storni abandona el tono paródico y argumenta su postura con la historización del tema. Por ejemplo, cuando quiere demostrar que la moda femenina es anticuada o que el luto es un rito social coyuntural, apela a ejemplos de otras culturas u otras épocas, como una estrategia

Revista Zona Franca- Centro de estudios interdisciplinario sobre las mujeres (CEIM)- Maestría poder y sociedad desde la problemática de género (MG), Rosario, Argentina. ISSN, 2545-6504 http://zonafranca.unr.edu.ar/index.php/ZonaFranca| Número 28 (2020). 
que logra quebrar con la naturalización de las costumbres. Una de las cuestiones que se deduce de estos textos, es la fe que tenía Storni en la modernización en la medida en que estaba convencida de que el feminismo era un fenómeno propio del progreso de la modernidad y, por lo tanto, era muy optimista respecto de la mujer del futuro.

Otro tópico que retoma Storni es el de la moda, la vestimenta contribuye, tanto a la constitución de una subjetividad femenina adecuada a la identidad de género, como a señalar su temible masculinización, fundamentalmente mediante el uso de pantalones. Su crítica se centra en un aspecto nodal: el arreglo del cuerpo para ser mirado. Storni distingue la vestimenta masculina de la femenina, porque la primera es moderna en tanto es práctica y cómoda para la vida urbana, y, por el contrario, la segunda es anticuada ya que apunta al agrado de la mirada masculina, y no, a la practicidad necesaria en esos tiempos. Además, en el caso del corsé, fundamenta los problemas de salud que este produce en el cuerpo de la mujer, argumento común y constante en las columnas femeninas, es más, en 1920, el cuerpo femenino es el objeto de una batalla entre los médicos higienistas y los defensores de la moda, como explica Armus (2009), pero, la preocupación de Storni no tiene que ver con esta puja masculina, sino con el hecho de que la vestimenta moldea la subjetividad femenina, por lo que ocupa no sólo el cuerpo, sino el pensamiento de las mujeres.

Retomando lo anterior, es en el tercer modo de nombrar al referente cuando Storni no disimula su enojo y apela a enunciados explícitamente descalificadores: niña inútil, impersonal, chica loro. Esta estrategia es predominante por lo que, sea en los títulos o en los textos, siempre aparece al menos una vez, lo que trae como consecuencia un efecto de mimesis paródica que abarca tanto a los nombres más neutrales - mujeres- como a los que provienen del falogocentrismo - bellos sexo-. La crítica explícita en el nombre elegido para la mujer doméstica es acompañada de otra estrategia que se reitera en las crónicas: una descripción detallada de la vestimenta, es decir, del cuerpo bajo la mirada masculina, en donde la superficie de

Revista Zona Franca- Centro de estudios interdisciplinario sobre las mujeres (CEIM)- Maestría poder y sociedad desde la problemática de género (MG), Rosario, Argentina. ISSN, 2545-6504 http://zonafranca.unr.edu.ar/index.php/ZonaFrancal Número 28 (2020).

Página 353 
la piel- ropa constituye el ser entero de la mujer. Por ejemplo, "Tipos femeninos callejeros" es una pormenorizada descripción de la vestimenta de una joven casadera que comienza por los pies y culmina con la cabeza. El recorrido del cuerpo, de abajo hacia arriba da cuenta de una jerarquía inversa que se evidencia con la ironía del final, ya que, cuando la cronista se cansó de la joven, le comenta a la lectora: "Por último os cansáis un poco de la chica-loro y la abandonáis en una esquina, no sin antes haber observado la movilidad de sus manos y la inteligencia de sus expresiones." (103) Storni acentúa la superficialidad de la joven al dejar a "la inteligencia" como el último detalle, procedimiento de indisimulada ironía, hasta de cierta irritación, que se refuerza con el nombre de la joven: chica-loro.

La superficialidad femenina no se reduce a una cuestión de género, sino, en coincidencia con Arlt, también, de clase. Me refiero a que alude, en versión femenina, al mito del ascenso de clase presente en $M^{\prime}$ hijo el dotor, obra teatral de Florencio Sánchez estrenada antes del Centenario. Esta fusión de valores de clase y de género son los que observa Tao Lao cuando, en relación con las profesoras, se detiene en la preocupación de éstas por la apariencia física, se ríe ante las crédulas féminas que suponen que allí reside la emancipación y afirma:

\begin{abstract}
La emancipación femenina de la monotonía del hogar en busca de nuevos campos para su actividad -según la frase en boga—ha tenido con gran frecuencia, como símbolo codiciado, una chapita. Esta chapita no es invención femenina. La introdujo al país por masculino, y acaso político conducto, una democracia pequeñita que substituyó el escudo por la chapa. (Storni, 2014: 202-3)
\end{abstract}

Así, las casas de moda son a los vestidos, lo que los conservatorios son a las chapitas: íconos de las fantasías de una clase que absorbe las ofertas del capitalismo. Storni es muy lúcida en detectar las ofertas mediante las que el mercado quiere hacerles creer a las mujeres que la llave de la independencia reside en un par de cursos. En verdad, muestra cómo el mercado encontró en la mujer, a

Revista Zona Franca- Centro de estudios interdisciplinario sobre las mujeres (CEIM)- Maestría poder y sociedad desde la problemática de género (MG), Rosario, Argentina. ISSN, 2545-6504 http://zonafranca.unr.edu.ar/index.php/ZonaFranca| Número 28 (2020). 
otra figura de cliente, la que, como el varón, desea trascender por el prestigio que da un título. En tal sentido, la profesora no es más que la versión femenina del doctor -M' hijo el dotor- y la chapita tiene el mismo sentido que la vestimenta: sostener una apariencia de clase. Storni no ve en estos cambios un avance de la mujer, sino, más bien, un movimiento de asimilación a la ideología de la clase media. Arlt realiza la misma crítica a la clase media, pero en relación con el varón. En una de sus aguafuertes, imagina la escena en la que una madre posee varias hijas y sólo un hijo que será el destinado a obtener un título, lo que acarrea visitas de sus compañeros de estudios $y$, en consecuencia, buenos candidatos para cada una de sus hermanas. Esto implica un cambio de casa, que Arlt metonimiza por medio de las persianas y las chapas de doctor rebosan de dinero frente al resto de los habitantes del barrio:

la chapa sólo sirve para que se extasíe la madre mirándola de reojo; la madre del dueño, y la niña que espera el novio. Porque al fin una casa con persianas metálicas, queda mejor con chapa de doctor que sin chapa. (134)

Los institutos de educación terciaria son una pieza más de la maquinaria de la domesticidad en dos sentidos: por un lado, porque el título posee una importancia social en relación a la clase, o sea, que es útil para sostener una pertenencia clasista $y$, por otro, porque en éstos, las mujeres no aprenden un oficio, sino que se siguen formando para ser "mujeres". En "La perfecta dactilógrafa", por ejemplo, Storni sostiene que son perfectas las que están vestidas como tales. De hecho propone una receta para hacer una dactilógrafa en donde la relevancia pasa por la vestimenta, por no tener más que un pájaro en la cabeza y por hacer un curso en una academia a tal fin. Parodia el tono normativo de los discursos orientados hacia las mujeres, que, a excepción de la ficción, abusan de una secuencia discursiva significativa: la instruccional. Storni relaciona estos relatos simples, cuya función es casi exclusivamente conativa, con la escritura para mujeres razón por las que los

Revista Zona Franca- Centro de estudios interdisciplinario sobre las mujeres (CEIM)- Maestría poder y sociedad desde la problemática de género (MG), Rosario, Argentina. ISSN, 2545-6504 http://zonafranca.unr.edu.ar/index.php/ZonaFranca| Número 28 (2020). 
incorpora para parodiar la construcción de lo femenino: el decálogo de la niña inútil, la receta de la perfecta dactilógrafa, el listado de los movimientos que permiten sostener la irreprochabilidad callejera. Imitando los manuales, compara a estas damas con los reyes y finaliza con una serie de instrucciones para quien desee fabricar este tipo de jóvenes:

Píntesele discretamente los ojos.

Oxigénesele el cabello.

Púlasele las uñas.

Córtesele un trajecito a la moda, bien corto.

Comprímasele el estómago.

Endurézcasele considerablemente los dedos anular y meñique.

Salpíquesela copiosamente de mala ortografía.

Póngasele un pájaro dentro de la cabeza (si es azul, mejor).

Envíesele durante dos o tres meses a una academia comercial.

(Hasta de cinco pesos por mes).

Téngasela pendiente de avisos comerciales durante uno, dos o tres años.

Empléesela por poca cosa.

(Storni, 2014: 199)

La forma y el estilo, de esta cita, invita a pensar en el dialogismo. La ubicación de un renglón debajo de otro insinúa un relato que podría ser un poema o un instructivo. Además, la musicalidad que producen las esdrújulas, parece imitar el teclear cortado y rabioso de la máquina y una aceleración del ritmo que va desde el arreglo físico hasta las academias, producen una dactilógrafa. Sutilmente, Storni describe la precaria situación laboral de las mujeres - a las dactilógrafas se las

Revista Zona Franca- Centro de estudios interdisciplinario sobre las mujeres (CEIM)- Maestría poder y sociedad desde la problemática de género (MG), Rosario, Argentina. ISSN, 2545-6504 http://zonafranca.unr.edu.ar/index.php/ZonaFrancal Número 28 (2020). 
emplea por poca cosa, a las acuarelistas se les paga dos pesos por día, las normalistas deben hacer largas colas para conseguir empleo-. Así las trabajadoras devienen máquinas funcionales al mundo laboral que no sólo les exige demasiadas horas de trabajo, sino que, también, les impone el deber de ser agradables a la mirada masculina.

Storni menciona la presencia significativa de las mujeres en el mundo del trabajo, sea en actividades previsibles -costureras, maestras-, o en otras más bien asociadas a los hombres -carpinteras, herreras-, con lo cual coloca en el centro de la escena a un sujeto no demasiado visible - la mujer trabajadora- o, más bien, cuya representación literaria y periodística está teñida por una mirada condenatoria o piadosa, pero nunca celebratoria. (Queirolo, 2018) Aún así, el objetivo de Storni no es tanto hacerlas visibles, sino, más bien, el de señalar que éstas, a pesar de la autonomía económica, siguen adoptando actitudes que las alienan como sujeto pleno. En cambio, la mujer que trabaja, en Arlt, es excepcional y, cuando aparece, se la describe con piedad, lo que pareciera contradecir la queja de Arlt ante las casaderas, que buscan que un hombre sostenga, económicamente sus existencias. Sin embargo, la contradicción desaparece si se tiene en cuenta que su voz, reenvía al discurso social falogocéntrico. Un ejemplo claro de la diferencia en el modo en que cada uno retrata a las trabajadoras, es evidente si se comparan dos textos: "La costurerita a domicilio" (Storni, 2014: 218) y "La muchacha del atado" (Arlt ,2000: 75) que, a su vez, aluden a un tercero que es, en el que se crea un personaje mítico de esta etapa, la costurerita que dio aquel mal paso que inmortalizara Evaristo Carriego en su poema homónimo.

La crónica de Storni comienza por aludir, irónicamente, a los versos de Evaristo Carriego: "Sale a la calle a la misma hora en que lo hacen las estrellas... esto ya está bastante bien y ha hecho gastar sesudas carillas a los poetas lánguidos." (218) Luego, continúa parodiando al referente, es decir, la costurerita, a la que despoja del pietismo carreguiano explicitando, en un gesto casi arltiano, la

Revista Zona Franca- Centro de estudios interdisciplinario sobre las mujeres (CEIM)- Maestría poder y sociedad desde la problemática de género (MG), Rosario, Argentina. ISSN, 2545-6504 http://zonafranca.unr.edu.ar/index.php/ZonaFranca| Número 28 (2020). 
verdadera intención que esconde: " $\mathrm{OOh}$ costurerita! Tu destino no es muy amplio, ya que el pozo en que te ahogas es una corbata ..." (218)

Storni, a través de la parodia de los tonos melodramáticos, alude al sueño dorado que promete un hombre profesional. La costurerita, dice la cronista, no desea, no se enamora, salvo de su propia idea de ascenso social. De ahí que haga hincapié en los paraísos artificiales que la costurerita recrea a partir de novelas y películas propias del melodrama. Storni critica la subjetividad femenina hegemónica y lleva a este tipo femenino más allá de la relación de noviazgo o casamiento, demostrando que la mujer se subjetiva en complementariedad con lo masculino, sólo por vocación de agrado, de sumisión ante el otro. Arlt, en cambio, despliega la guerra de los sexos en esta serie de aguafuertes, pero, en otras, matiza el sarcasmo exasperado que le provocan las mujeres, y la tentación piadosa que siente ante los giles, y aparecen esposas víctimas de sus maridos, obreras explotadas, mujeres profesionales. Puntualmente, en "La muchacha del atado", recrea el mismo personaje femenino, pero abandona la mirada cínica para dejarse vencer por la piedad, la pena, que le produce esta muchacha, pobre, que trabaja.

Todos los días, a las cinco de la tarde, tropiezo con muchachas que vienen de buscar costura. Flacas, angustiosas, sufridas. El polvo de arroz no alcanza a cubrir las gargantas donde se marcan los tendones; y todas caminan con el cuerpo inclinado a un costado: la costumbre de llevar el atado siempre del brazo opuesto:

Y los bultos son macizos, pesados: dan la sensación de contener plomo: de tal manera tensionan la mano. No se trata de hacer sentimentalismo barato. No. , pero más de una vez me he quedado pensando en estas vidas, casi absolutamente dedicadas al trabajo. Y, sino, veamos. (Arlt, 2000: 73)

Esta mirada de la feminidad, se repite, luego, en la ficción de otros escritores: la mujer temible es la de clase media, la doméstica, pero, cuando el tema en

Revista Zona Franca- Centro de estudios interdisciplinario sobre las mujeres (CEIM)- Maestría poder y sociedad desde la problemática de género (MG), Rosario, Argentina. ISSN, 2545-6504 http://zonafranca.unr.edu.ar/index.php/ZonaFrancal Número 28 (2020). 
cuestión no es el matrimonio, y se refiere a una mujer de pocos recursos, predomina la mirada pietista de clase, que oculta la mirada de género. En otras palabras, si la novia o la suegra son las vividoras de los hombres, la que trabaja, en cambio, es una víctima del capitalismo e, incluso, de los otros hombres de la familia. Así, como Arlt no ve el sometimiento de las mujeres a los ideales de la domesticidad, tampoco ve que estas muchachas, también, reproducen esos valores. Al contrario, en consonancia con Carriego y con los escritores de Boedo, las victimiza.

La diferencia con Storni es, entonces, radical. A pesar de la heterogeneidad sugerida, la cronista ve en las trabajadoras, la obsesión femenina de sostener la apariencia para el agrado de la mirada masculina y, en detrimento de la profesión, es decir, que demuestra, con las palabras de Pateman (1994), la continuidad del contrato sexual por el que las mujeres emancipadas siguen subordinadas al varón. En cierta manera, podemos decir que no le interesa tanto denunciar la dominación masculina como acentuar la internalización del sometimiento por parte de las mujeres, por eso, el eje sigue puesto en la descripción de los cuerpos. Además, sin necesidad de circunscribir a la mujer a una actividad laboral o clase social, y, colocándola en un espacio que supera la perfección de la dactilógrafa, la cronista dedica varios textos crónicas a la mujer doméstica en estado puro. Esta es la impersonal o irreprochable que "circula a cada paso por las calles de Buenos Aires, hueca como las cañas, como ellas flexibles al halago, como ellas alargada de inútil orgullo de obscura vanidad" (Storni 2014, 217). Así, se propone una fusión entre los comportamientos corporales y la vestimenta en tanto recurso útil para señalar cómo lo corporal, en tanto conjunto de movimientos mecanizados, ocupa la mente femenina de tal modo que logra un efecto de ausencia de personalidad. La ironía de la voz narrativa se intensifica al producirse este movimiento que va desde lo público a lo privado: la mujer de los movimientos perfectos en las calles, en su hogar invertía una cantidad considerable de su tiempo en reforzar y lograr este efecto. El aparentar ser como la mujer de la clase social superior, como indican las revistas o como las estrellas de cine, era un trabajo que ocupaba el tiempo de éstas en el

Revista Zona Franca- Centro de estudios interdisciplinario sobre las mujeres (CEIM)- Maestría poder y sociedad desde la problemática de género (MG), Rosario, Argentina. ISSN, 2545-6504 http://zonafranca.unr.edu.ar/index.php/ZonaFranca| Número 28 (2020).

Página 359 
espacio privado. En la calle, la irreprochable es un blando descanso para la mirada masculina y, en la intimidad de su hogar realiza un enorme esfuerzo por ser lo que el ojo masculino desea ver. Para acentuar el carácter performativo de la feminidad, la cronista transcribe una lista de los movimientos femeninos que sostienen la perfección:

Miradas al espejo (distintas clases, tamaños y lunas)

Miradas en los cristales de las vidrieras

Estiramiento de guantes

Cuidado de que los alfileres no escapen de su sitio

Humedecimiento de los labios

Afirmación especial de la pechera con 5 un tironcito

Llevada de las manos a las horquillas que sostienen el velo

Reposición de polvos (muy discreto)

Enderezamiento de las cuchillas de las medias

Lustrada furtiva de zapatos, restregándolos contra la parte posterior de la pierna

Imprevistos con respecto a carteras, cuellos, pliegues, etc.

(Storni, 2014: 238-39)

Una vez más, casi como si escribiera un poema, Storni da cuenta de las miradas pendientes de sí misma, los imperceptibles movimientos de las manos y los pies, el control sobre los accesorios. Esta cita es la versificación de los

Revista Zona Franca- Centro de estudios interdisciplinario sobre las mujeres (CEIM)- Maestría poder y sociedad desde la problemática de género (MG), Rosario, Argentina. ISSN, 2545-6504 http://zonafranca.unr.edu.ar/index.php/ZonaFrancal Número 28 (2020). 
movimientos mecanizados y contabilizados que culminan con la obtención de un pretendiente. Claro está que este cuadro desafía a los científicos, se ríe de los higienistas y recuerda la monotonía previsible de algunos trabajos. La irreprochable ha incorporado la mirada masculina y se controla, como si fuera una máquina. La joven se pasea por las tiendas de ropa de la calle Florida y allí se produce una transformación tal, que la poca humanidad que les quedaba se ve alienada por una serie de objetos que cobran vida y dominan sus conductas: los zapatos las llevan, el ascensor inteligente se detiene en el piso adecuado, los maniquíes atraen sus miradas sin que ellas puedan despegarse, como se lee en "Las crepusculares".

\begin{abstract}
El ascensor, que es inteligente, sabe que de 17 a 18 deberá detenerse muchas veces en un piso especial. Los zapatitos en epidemias lo han golpeado nerviosamente mientras hacia allí los transportaba, y él ha aprendido el lenguaje de sus suelas. Es por eso que, a la menor presión del botón, se para y deposita su preciosa carga en el codiciado lugar de las muñecas de carne y hueso que ofician de modelos. (Storni ,2014: 207)
\end{abstract}

La subjetividad doméstica está marcada por su construcción especular, en función de la mirada masculina, por rendir culto a la apariencia, por hallar en el esposo a quien complete su identidad. Sin embargo, Storni complejiza, aún más, esta cuestión ya que señala la intromisión de otro aspecto: la expansión del capitalismo. Es decir, que la mujer doméstica es funcional al crecimiento de la sociedad de consumo que las seduce, adjudicándoles un rol absolutamente pasivo. El varón casado, para Arlt, ya no es el bien preciado, sino que es un pobre hombre que ve amenazada su fortuna por la esposa consumidora. La máquina de la paranoia arltiana se pone en acción para denunciar otra competencia entre varones: el esposo versus el comerciante, como se lee en "Encantos de las calles del centro"

Revista Zona Franca- Centro de estudios interdisciplinario sobre las mujeres (CEIM)- Maestría poder y sociedad desde la problemática de género (MG), Rosario, Argentina. ISSN, 2545-6504 http://zonafranca.unr.edu.ar/index.php/ZonaFrancal Número 28 (2020). 
En Buenos Aires los 'dorimas' son esclavos de sus esposas, las esposas esclavas de los tenderos, y los tenderos hombres omnipotentes, melifluos y terribilísimos, que se tragan las señoras, los maridos y las ganancias de los maridos. (62)

En cambio, Storni, en "Las crepusculares" no vincula a éstas, las consumidoras, con sus maridos, sino que las muestra como seres seducidos por aquellas luces de las telas sugestivas en el cuerpo de otra mujer: la modelo.

En la crónica, la multitud femenina la conforman las cientos de irreprochables automatizadas bajo los sensuales movimientos de la modelo que, según Salomone (2006), alude a cierta fascinación de la imagen femenina propia de las divas del cine de Hollywood. Además, la ola como cuerpo sin voluntad, hipnotizado, sugiere a las féminas arrastradas por el consumo compulsivo y hasta se podría pensar una analogía entre la modelo y el líder, las mujeres y la masa, si se piensa que, en la época, el fascismo era una cuestión latente, que, a su vez, es uno de los discursos que construyen el delirio del Astrólogo en Los siete locos de Arlt.

Tanto Arlt como Storni retoman el emblemático tópico de la masividad, de distinta manera. Storni, ante las conductas autómatas de las consumidoras y Arlt, ante la seriación de las empleadas por parte del mercado laboral. No obstante, la imitación se recorta como una de las condiciones necesarias para llegar a ser una mujer en la vida pública. La exposición de las mujeres en el espacio público, suponía una amenaza a la moral y a la virtud, cuestión transmitida a través de numerosos discursos - artículos femeninos, manuales, folletines- que oficiaban de controladores de la subjetividad y corporalidad femenina. La conducta imitativa no sólo produce el efecto del vacío de personalidad, sino que, también, para Storni, puede provocar que la mujer se transforme en un ornitorrinco. La cronista no deja de acentuar que estas características de la feminidad no son esenciales, sino que forman parte de una pose, de un trabajo de adaptación al modelo hegemónico ya que en "La joven bonaerense" retoma el comentario de un extranjero, George Clemenceau, sobre la superficialidad de la mujer para aclarar que "Toman por

Revista Zona Franca- Centro de estudios interdisciplinario sobre las mujeres (CEIM)- Maestría poder y sociedad desde la problemática de género (MG), Rosario, Argentina. ISSN, 2545-6504 http://zonafranca.unr.edu.ar/index.php/ZonaFranca| Número 28 (2020). 
inferioridad lo que es pereza, y por incapacidad lo que es timidez" (247). Así, la pereza de las manicuras y la timidez de las profesoras señalan la distancia definitiva de la identidad de género ya que no se trata de una condición biológica, sino de un efecto producido por la heterosexualidad obligatoria.

\section{Bibliografía}

ARLT, Roberto. 2000. Aguafuertes porteñas: Buenos Aires, vida cotidiana. Buenos Aires: Editorial Losada.

ARMUS, Diego. 2009. El viaje al centro: "Tísicas, costureritas y milonguitas en Buenos Aires, 1910-1940. Buenos Aires: Red Salud Colectiva.

BRAIDOTTI, Rosi. 2015. Feminismo, diferencia sexual y subjetividad nómade. Barcelona: Gedisa. https://elibro.net/ereader/elibrodemo/61112.

BUTLER, Judith. 1999. El género en disputa. Barcelona: Paidós.

S/A Congreso Femenino Internacional de la República Argentina, y Asociación «Universitarias Argentinas.», eds. 2008. Primer Congreso Femenino Internacional de la República Argentina: historia, actas y trabajos. Córdoba, Argentina: Universidad Nacional de Córdoba.

DIZ, Tania. 2006. Alfonsina periodista: ironía y sexualidad en la prensa argentina (1915-1925). Buenos Aires: Universidad de Buenos Aires, Centro Cultural Rector Ricardo Rojas.

FOUCAULT, Michel. 1990. Historia de la sexualidad, 1: La voluntad de saber. Barcelona: siglo veintiuno editores.

LÓPEZ, Elvira. 2009. El movimiento feminista: primeros trazos del feminismo en Argentina. Buenos Aires: Biblioteca Nacional.

MASOTTA, Oscar. 1982. Sexo y traición en Roberto Arlt. Buenos Aires: Centro Editor de América Latina.

MÉNDEZ, Mariela. 2017. Crónicas travestis: el periodismo transgresor de Alfonsina Storni, Clarice Lispector y María Moreno. Rosario: Beatriz Viterbo.

NARI, Marcela. 2004. «Políticas de maternidad y maternalismo político: Buenos Aires, 1890-1940». Buenos Aires: Ed. Biblos.

Revista Zona Franca- Centro de estudios interdisciplinario sobre las mujeres (CEIM)- Maestría poder y sociedad desde la problemática de género (MG), Rosario, Argentina. ISSN, 2545-6504 http://zonafranca.unr.edu.ar/index.php/ZonaFrancal Número 28 (2020). 
PATEMAN, Carole. 1994. El contrato sexual. Barcelona: Anthropos.

QUEIROLO, Graciela. 2018. Mujeres en las oficinas: trabajo, género y clase en el sector administrativo (Buenos Aires, 1910-1950). Buenos Aires: Ed. Biblos.

SALOMONE, Alicia. 2006. Alfonsina Storni: mujeres, modernidad y literatura. Buenos Aires: Corregidor.

STORNI, Alfonsina. 2014. Escritos: Imágenes de género. Letras y pensamientos en el Bicentenario. Villa María: Eduvim.

Revista Zona Franca- Centro de estudios interdisciplinario sobre las mujeres (CEIM)- Maestría poder y sociedad desde la problemática de género (MG), Rosario, Argentina. ISSN, 2545-6504 http://zonafranca.unr.edu.ar/index.php/ZonaFrancal Número 28 (2020). 